Article

\title{
Is the Electric Vehicle an Attractive Option for Customers?
}

\section{Israel García * and Luis Javier Miguel}

Systems Engineering and Automatic Control Department, University of Valladolid, Paseo del Cauce s/n. 47011 Valladolid, Spain; E-Mail: luimig@eis.uva.es

* Author to whom correspondence should be addressed; E-Mail: israel.garcia@renault.com; Tel.: +34-656-273165; Fax: +34-983-423358.

Received: 7 November 2011; in revised form: 23 December 2011 / Accepted: 4 January 2012 / Published: 12 January 2012

\begin{abstract}
As a new technology, electric mobility has the potential to achieve a reduction in $\mathrm{CO}_{2}$ emissions and contribute to the transition from the current transportation system to a better one, environmentally speaking. The objective of the paper is to aid the necessary decision-making for the adoption and development of electric vehicles in Spain, taking the time horizon of 2020. This will be achieved by building a System Dynamics model for various scenarios that will be used for the analysis and comparison of various dynamic variables, as well as to determine how, and to what extent, they will influence the number of electric vehicles that will run on Spanish roads in the coming years, focusing on the cost variable.
\end{abstract}

Keywords: electric vehicles; batteries; $\mathrm{CO}_{2}$ emissions; electric vehicle costs

\section{Introduction}

Road transport today is responsible for a significant and growing share of global $\mathrm{CO}_{2}$ emissions. In 2008 , the transport sector consumed $38 \%$ of the total energy used in Spain. Within the sector road transport is still almost entirely dependent on oil-derived fuels (about 98\%), and is therefore highly vulnerable to possible oil price fluctuations and supply disruptions. The transport sector is responsible for more than $25 \%$ of $\mathrm{CO}_{2}$ emissions in Spain, and road transport is responsible for $90 \%$ of the $\mathrm{CO}_{2}$ emissions in this sector, with an energy consumption of about $80 \%$ of the sector's total [1].

Looking at these data, a change process in the automotive sector which involves a reduction in both $\mathrm{CO}_{2}$ emissions and energy consumption of vehicles running in Spain is necessary. To achieve this, the 
government has begun to develop strategies to drive the change, among which one is the promotion of alternative propulsion technologies to conventional ones (MOVELE project).

A transition to EV (electrically-powered vehicles) has been proposed because they have the potential for significantly reducing $\mathrm{CO}_{2}$ emissions. This can be justified, in the first place, since the electric motor is more energy efficient than the internal combustion engine [2]. The "Well-To-Wheel" model is used to compare emissions from both engines [3]. Besides the direct $\mathrm{CO}_{2}$ emissions from the exhaust, the use of a vehicle also causes indirect $\mathrm{CO}_{2}$ emissions emanating from the fuel supply chain. The sum of the direct emissions and the emissions from the fuel chain are the Well-To-Wheel. In the case of the internal combustion engine, only a performance that at best does not reach $20 \%$ can be obtained, while for the electric vehicle, with electric power from the current mix, it is about $30 \%[2,4]$. The electric vehicle produces no polluting emissions during its use due to the electric motor. However, electric vehicles will not be completely exempt from emissions as such. There will be some emissions to compute, depending on where electrical energy is obtained. Accordingly, for the electric vehicle to generate no emissions during its use, the electricity must come from $\mathrm{CO}_{2}$-free sources, such as renewable sources.

As expected, the change will not be easy. The task is certainly complex: changing consumer habits after many years of using one kind of vehicle with a range of benefits that, in some way, will cease to exist.

Regarding the conventional vehicle, electric vehicles currently available usually have a higher purchase price and shorter lifetime than conventional power trains [5]. Electric vehicles are in the early phases of the adoption process [6] and it is important to analyze whether the characteristics of the electric vehicle actually meet the consumers' needs.

As mentioned, the first deterrent the customer finds is the purchase price difference (essentially the cost of the battery) described by previous works [7]. However, this cost is compensated by the lower cost of electricity compared to gasoline and the lower cost of maintenance [8]. This paper examines individuals' motivations when purchasing vehicles, focusing upon what economic factors would encourage consumers to purchase an electrical vehicle or a conventional vehicle.

This research attempts to ascertain, from an economic point of view, if reductions in fuel costs, mechanical damage to the engine (due to its simplicity), or greenhouse gas emissions would encourage individuals to purchase an electric or a conventional vehicle in the next 10 years. To do this, we consider no only the costs when acquiring the vehicle, but also the costs over its useful life (including oil and electricity price fluctuations, taxes, garage conditioning for recharging, etc.), in order to determine the years of repayment on the purchase of an electric vehicle compared to a conventional one.

Nowadays, there is much literature on electric vehicles, including some very detailed works, such as "On the Road 2035" [2], the Electric Power Research Institute (EPRI) Reports [9-11], and the research by the Institute of Transportation Studies at UC Davis [12,13]. This paper, however, mainly examines the economic influence at the time of purchasing the vehicle, but also the costs over its lifetime use, focused on the Spanish context. Regarding the Spanish sector, there are not many policymaker studies [14], and even fewer focused on the policies necessary for the integration of electric vehicles in society and the methodology used, a question that motivates the creation of this paper. 


\section{Work Methodology}

The potential future developments of the electric vehicle sector are still unknown, making it impossible to analyze all the influential elements, so to forecast the adoption process of the electric vehicle, an approximation must be used. In a previous work by Geels [15], it is explained that the conceptual perspective of the technology transition to the electric vehicle is fairly complex. "Can it be made operational for empirical research? The proof of the pudding is in the eating, i.e., use the perspective for empirical analyses of dynamics of socio-technical systems". This means that there is an abstract representation of technology transitions. However, a more empirical version of this process is required.

The methodology used in this project is the creation of a simulation model through which different policy options are played out in different scenarios, leading to different results. Due to the complexity of the model and the variety of interactions between its component variables, the research method used to create the model and its analysis is System Dynamics. System Dynamics is a method that challenges us all how to move from generalizations (abstractness) about accelerating learning and system thinking to tools and processes that help us to understand complexity, design better operating policies, and guide change in systems (concrete) from the smallest business to the planet as a world [16].

It is not easy to model the process of diffusion of a new technology. However, System Dynamics is an appropriate tool to model it. "System Dynamics is used for the analysis of policy and strategy, with a focus on business and public applications. Furthermore, System Dynamics is a perspective and set of conceptual tools that enable us to understand the structure and dynamics of complex systems" [16]. This modeling technique provides more concreteness to the abstract description of technology transitions.

System Dynamics models facilitate the development and testing of policies that lead to improved system behavior. It is very important to know that System Dynamics is not a tool designed to predict the future, but a tool to understand the present: to understand the variables that interact and how they can influence each other.

A causal loop diagram, as shown in Figure 1, is the tool used in System Dynamics to visualize the causal relations between variables in a system. A positive causal influence, symbolized by "+", means that if the influencing variable (which is at the arrow's origin) increases, then the influenced variable (which is at the arrow's head) increases. A negative causal influence, symbolized by "-", means that if the influencing variable increases then the influenced variable decreases.

Figure 1. Casual loop diagram example.

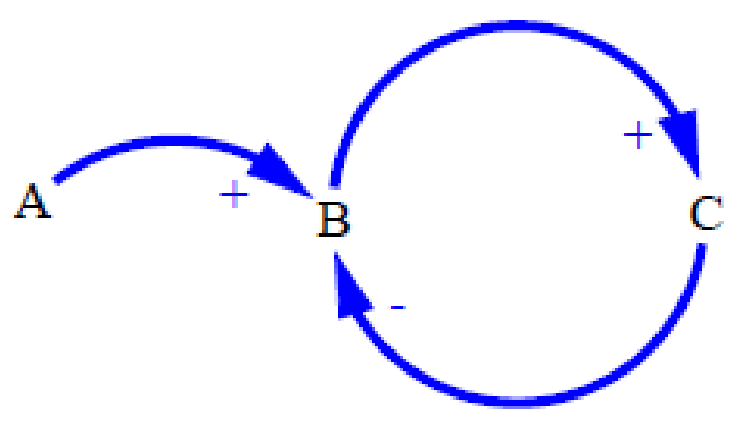


With the causal loop diagrams we are able to visualize the feedback loops of a model. A feedback loop exists when a variable can influence its own value over time. In a positive, or amplifying, feedback loop, an increase in the variable will lead to a further increase of the variable over time. In a negative, or balancing, feedback loop an increase in a variable will lead to a decrease over time.

\section{General Model Description}

Figure 2 shows a general vision of the model's blocks and the interrelations between them.

Initially, there is a demand for electric vehicles. The vehicles manufactured must satisfy this demand. For the study, the vehicles manufactured for the Spanish market are considered, not taking into account the country in which they are manufactured. As the number of manufactured vehicles increases, the electric vehicle park will also grow, which will clearly affect $\mathrm{CO}_{2}$ emissions included in the environmental block and, subsequently, the policies options that the Government can use, either in the form of subsidies or special cargo rates, or an increase in the number of charging points, etc. The Government's policies will also be influenced by the environmental block, since the subsidies will be amended to reduce $\mathrm{CO}_{2}$ emissions to the atmosphere.

The Government's policies will significantly influence the cost that the potential customer perceives when purchasing electric vehicles, due to subsidies, and the costs over the life of the vehicle by reduced overnight charge rates, etc. In addition, the Government's policies will also affect the attractiveness of electric vehicles for the consumer in comparison to a conventional vehicle. This is motivated by the advantages or disadvantages that buying an electric vehicle may have, such as the autonomy, the lack of charging points, the cost of recharging the electric vehicle, etc.

Both the cost of the electric vehicle and its attractiveness to the consumer are directly related to the evolution that the technology of electric vehicles will have in the coming years. This is because a very important part of the purchase price of electric vehicles is the battery, and one of the main factors of concern for potential buyers is the autonomy they have.

To close the loop, electric vehicle demand will evolve over time, influenced by the amount of money the buyer will have to pay (at the initial time of purchase and throughout the life of the vehicle), and its attractiveness.

It is interesting to note that, in global terms, the evolution of the technologies associated with electric vehicles will also be influenced by the demand for them. In this study, it is not considered in this way, since the demand for electric vehicles in Spain is very small in comparison to global demand, which will motivate technological advances in this field.

The same happens with other blocks, that is, the system being treated is not an isolated system. The global market for electric vehicles will influence the system, but for this study, we have considered various data as exogenous variables, i.e., the value of these variables is determined by factors not included in the model being used. According to this, we can determine that the study covers worldwide developments. 
Figure 2. General model schema.

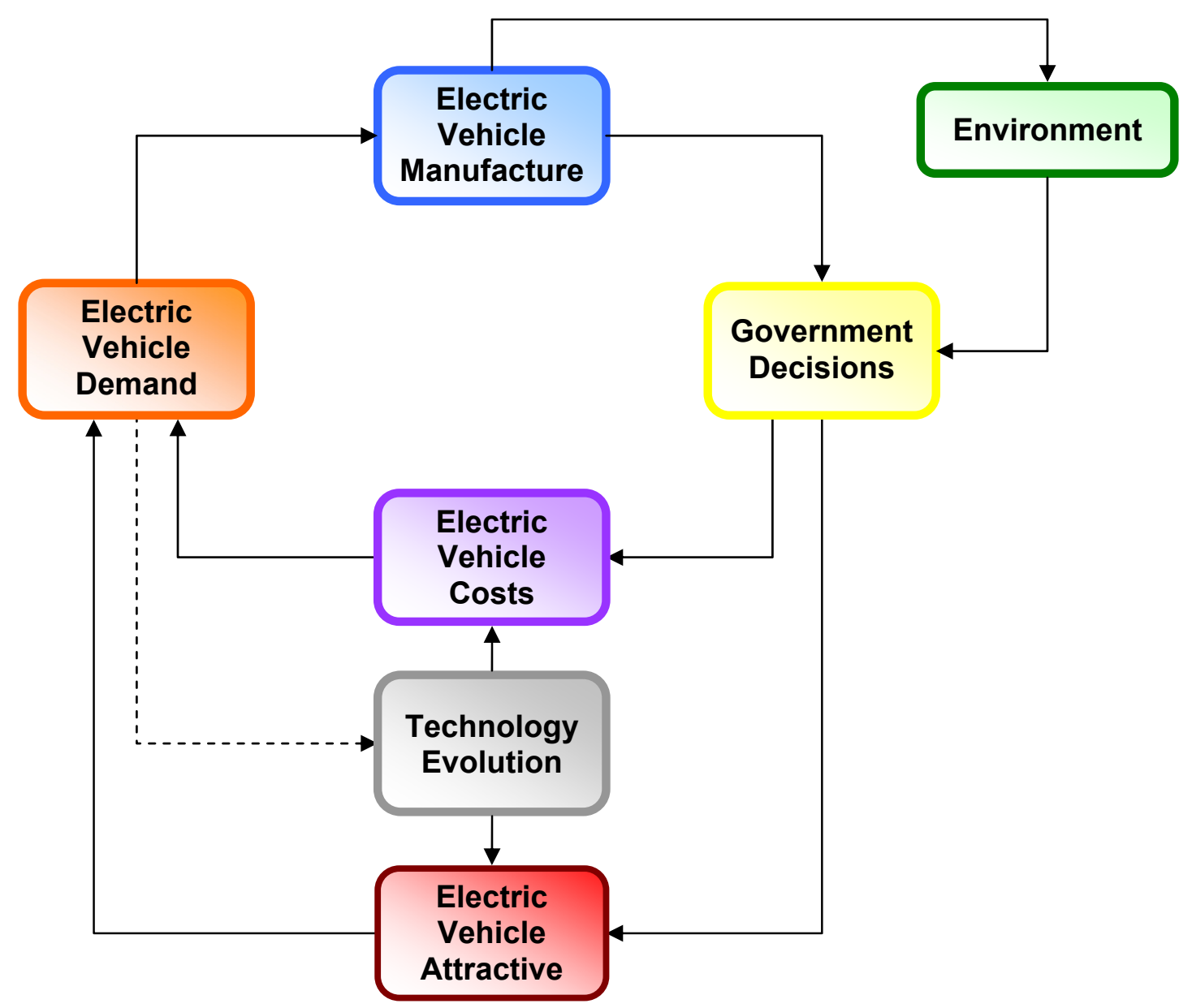

\section{Block: Electric Vehicle Cost}

Although all the blocks are treated in the full study, for this paper, only the block containing the electric vehicle costs and its comparison with the conventional vehicle are explained. This model's block analyzes the costs of both electric and conventional vehicles at time of purchase by the customer and during the vehicle's lifetime. To do this, data is considered as an evolution of oil prices and electricity, maintenance costs, etc.

To analyze the economic efficiency of electric vehicles, the total costs of ownership (TCO) of both vehicles (electric and conventional) are analyzed [17]. TCO describes costs over the lifetime of a vehicle: purchasing costs and costs of operation (annual costs). A comparison of the TCO of electric vehicles with the reference vehicles provides indications of the economic efficiency of the former. The battery plays a major role in the TCO, so battery costs are looked at in detail.

The model has been divided into four sections: the purchase cost of the electric vehicle, the cost of the electric vehicle during its life, the purchase cost of the conventional vehicle, and the cost of operation of the conventional vehicle during its life. The total cost of electric vehicles consists of the sum of the purchase cost and the running costs of electric vehicles. In the same way, the total cost of conventional vehicles consists of the sum of the purchasing cost and the running costs of conventional vehicles. Figure 3 shows a summary of the overall functioning of the block. 
Figure 3. Schema of the electric vehicle block.
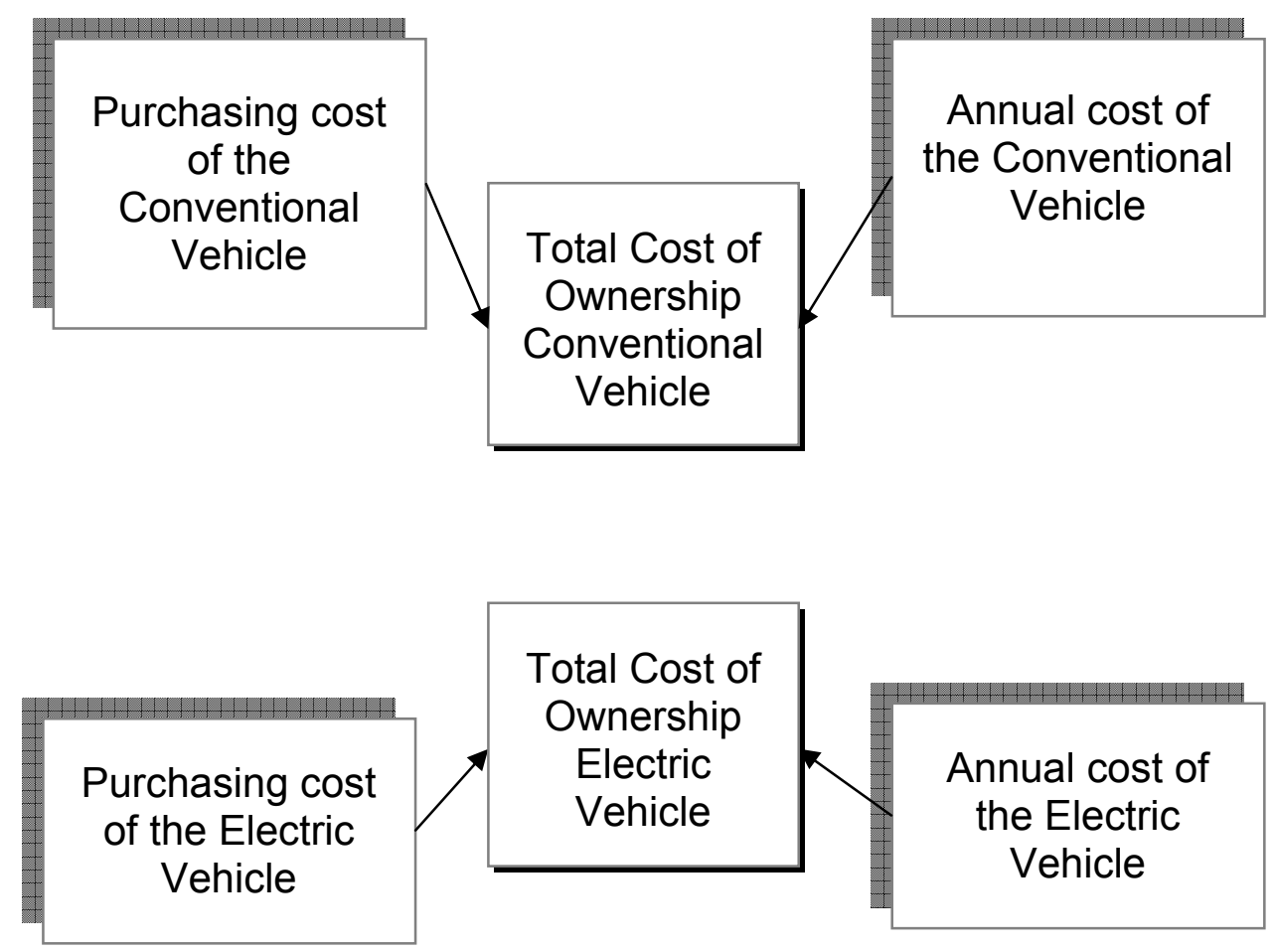

The simplest section corresponds to the purchasing cost of the conventional vehicle by the customer. The conventional vehicles that can potentially compete with electric vehicles are relatively compact, so that, based on statistical data and purchasing trends in Spain, a reference price has been set for the conventional vehicle.

Once the reference value of the conventional vehicle has been set, the purchase cost of electric vehicles is determined by the reference value of the conventional vehicle, adding some kind of costs, but also eliminating others. Figure 4 shows a simplified diagram of the electric vehicle.

Figure 4. Electric vehicle schema.

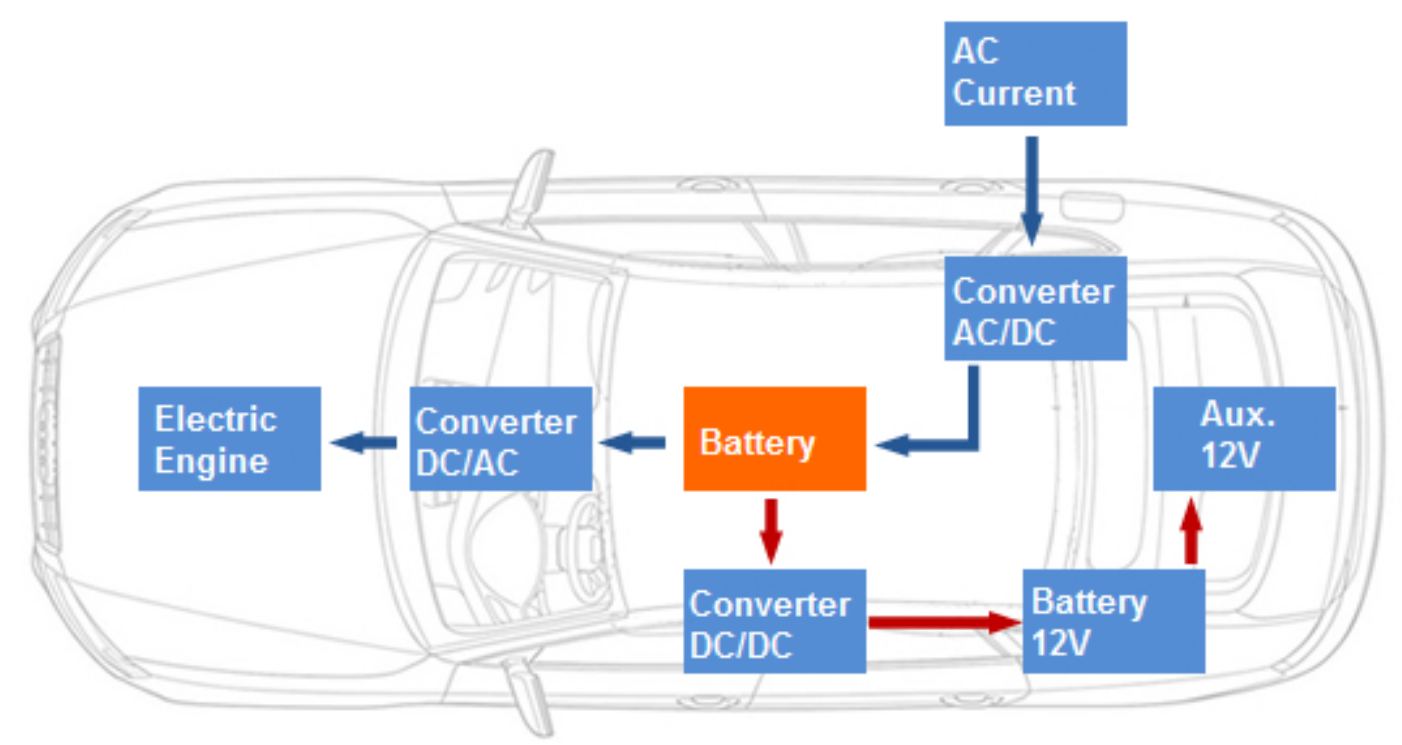


The most significant additional costs of electric vehicles will be the necessary wiring and charger for charging the vehicle both slowly and rapidly [2], the different motor drive required and, of course, the cost of the batteries, which is the most significant contributor.

According to the available information [2], the extra charger and wiring costs in Spain will cost about $480 €$, while the cost of the motor drive will be $160 €$. In contrast, the motor simplification leads to a reduction of product cost. It is estimated that a gasoline engine will cost about 2,400 $€$, while the electric motor will only cost $1,200 €$, so there is an interesting reduction.

Moreover, the electric motor requires an additional component: an engine control system that allows the required torque or speed to be adjusted for every load point. The cost of this control is now about $1,020 €$ but a significant reduction is expected to result from mass production, with the price reaching $70 \%$ of its current value [18].

In electric vehicles, an additional component called a DC/DC converter is also required. This is used to convert the voltage from $100 \mathrm{~V}$ to $12 \mathrm{~V}$, which is necessary for the auxiliary systems required for the vehicle. The cost will depend heavily on the input voltage, but should be around $300 €[18]$.

In addition to this converter, an $\mathrm{AC} / \mathrm{DC}$ converter, used to recharge the battery by connecting it to an external AC power, is also needed. The cost of this converter is approximately $400 €[18]$.

One of the key factors in the evolution of the purchasing price of electric vehicles will be the reduction in the battery costs in the coming years. To predict these developments, there is a model which includes forecasted values of the reducing cost of the $\mathrm{kWh}$, and the evolution that the battery capacity will undergo in the coming years in both optimistic and pessimistic scenarios [19], developed in the Technology Block, mainly using works by Kromer and Heywood [20], Duvall [9] and Kurani [13].

To calculate this, it is also necessary to know the battery's capacity and the manufacturing cost of the battery. For the cost estimate, we use a graph of the expected price per kWh reduction over the next 10 years. To do this, we use the following reference data [19] from the Technology Block.

As can be seen in the graph (Figure 5), there are several scenarios for the cost of batteries, but what is quite clear is that they provide a very significant decrease. So far, the rate of decline in the cost of the batteries has been between $6 \%$ and $8 \%$ per year [21]. Many analysts predict that the price will continue to fall over the next 10 years in the same way, due to increased production volumes.

A cost that has also been considered for this study is the upgrading cost of the garage, in appropriate cases, to be able to recharge the battery there. Taking into account the potential population living in apartment buildings, in single-family houses, and the Spanish law, the upgrading cost will vary significantly.

According to a RACE (Royal Automobile Club of Spain) study [22], 80\% of the population would choose the nighttime to charge electric vehicles, so to simplify the model it is assumed that in these early years of commercialization of electric vehicles a customer acquiring an electric vehicle will also charge it in his garage during the night.

At this point it is very important to know whether the available garage is individual or community property, because, though the charging systems are similar, the method for calculating electricity consumption differs considerably in each case. On the one hand, in an individual garage, all electricity consumed (either by charging an electric vehicle or by having a computer connected, or air conditioner for example) will be billed to a single consumer. On the other hand, in the community garage, it is necessary to discriminate the source of consumption in order to know whom it will be charged to. 
Figure 5. Forecast of the battery price [19].

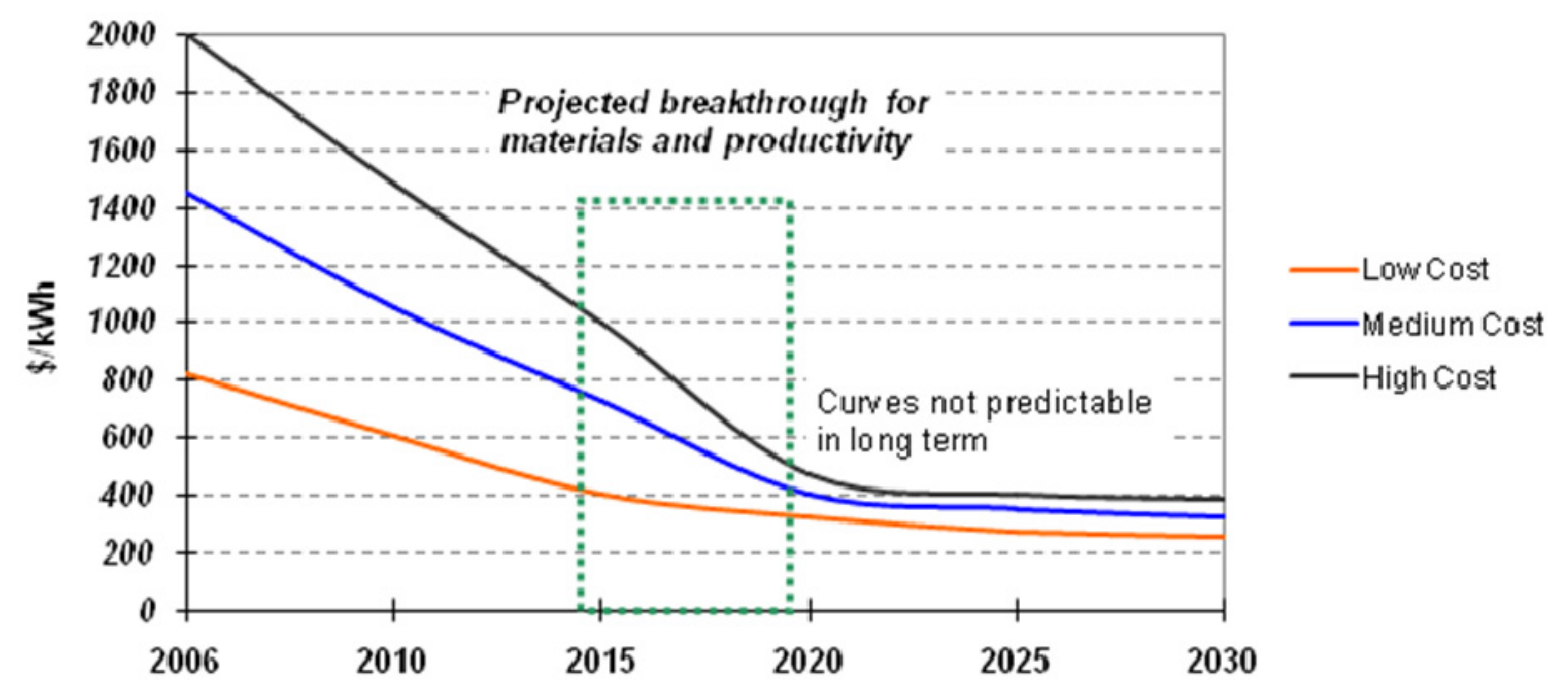

According to data from the INE (National Institute of Statistics), $28 \%$ of the population lives in a single-family house, while $72 \%$ live in a flat. While not $100 \%$ of the population has a garage, this study has ignored that fact, since, according to all surveys [22], the potential client owns a garage.

In a single-family house garage, it is simply necessary to have a $230 \mathrm{~V}$ and 16 A household outlet, for which the cost has been estimated at approximately $100 €$ for a basic installation in an environment with electric service available.

In the case of collective garages, the required system is slightly more complex. While the law already authorizes and provides facilities in such collective garages (Law 49/1960, of July 21st), in this case, as well as having a socket of similar dimensions to those of an individual garage, a counter to discriminate the source of consumption is also needed. Thus, the residents pay the total electricity consumed, then that cost is distributed among users of existing electric vehicles in proportion to their consumption. However, in anticipation of widespread recharging of electric vehicles in collective garages, several brands of electric circuits are beginning to market solutions for collective garages such as charging system monitoring interfaces, or in its simplest case, individual recharging points activated by an identification system to eliminate potential vandalism.

In view of the electrical systems that must be installed in the collective garage, it is logical to expect that the cost of installation will be very superior to that in the individual garage. Taking into account actual budgets, and also taking into account the need for the implementation of a certification for it to be a new installation, the estimated average cost for charging an electric vehicle in a community garage is $900 €$.

A final factor to consider in the purchase price of electric vehicles is the subsidies that the government can provide at the specific time of purchase. For this calculation, we use three interrelated variables: the value of the subsidy, the budget that the IDAE (Spanish Energy Institute) can spend on subsidies for the purchase [1] and, finally, the money already being spent on subsidies.

Currently, 7,000 Euros has been taken as the purchase subsidy [1], which is the average subsidy for this type of vehicle in Spain. The government budget is 240 million Euros in 2011 and 2012. For 2012, no data or estimations of subsidies have yet been delivered. 
Once the purchasing costs for both vehicles have been established, it is now necessary to determine the running costs, which in both cases are mainly the cost of fuel (and its consumption) and the cost of vehicle maintenance.

For the conventional vehicle, the analysis of the annual fuel consumption begins with the average consumption of an internal combustion vehicle today in Spain, taking into account the average consumption of diesel and gasoline vehicles, as well as the percentage of population using each kind of vehicle. It is considered that the average consumption of a gasoline engine is 8 liters per $100 \mathrm{~km}$ (20.4 miles per gallon), while the average consumption of a diesel vehicle is 6 liters per $100 \mathrm{~km}$ (39.2 miles per gallon) [23]. Given that in Spain 53\% of vehicles are gasoline and 47\% diesel [24], the current average consumption of an internal combustion vehicle is the product of the consumption of gasoline vehicles times their percentage product, added to the consumption of diesel vehicles multiplied by their percentage. After obtaining some reference data, some improvements in the efficiency of the engines that will be developed in coming years have been added as well as aerodynamic improvements that will dynamically change vehicle consumption $[2,18]$.

Estimating how oil prices will evolve over the next 10 years is a task of great complexity with a high rate of failure. The price of oil depends on many factors. There are few reserves in the World and it is a scarce commodity (referring to what can be extracted with current technology, and whose extraction would be profitable at current oil prices).

Figure 6. Oil price evolution [25].

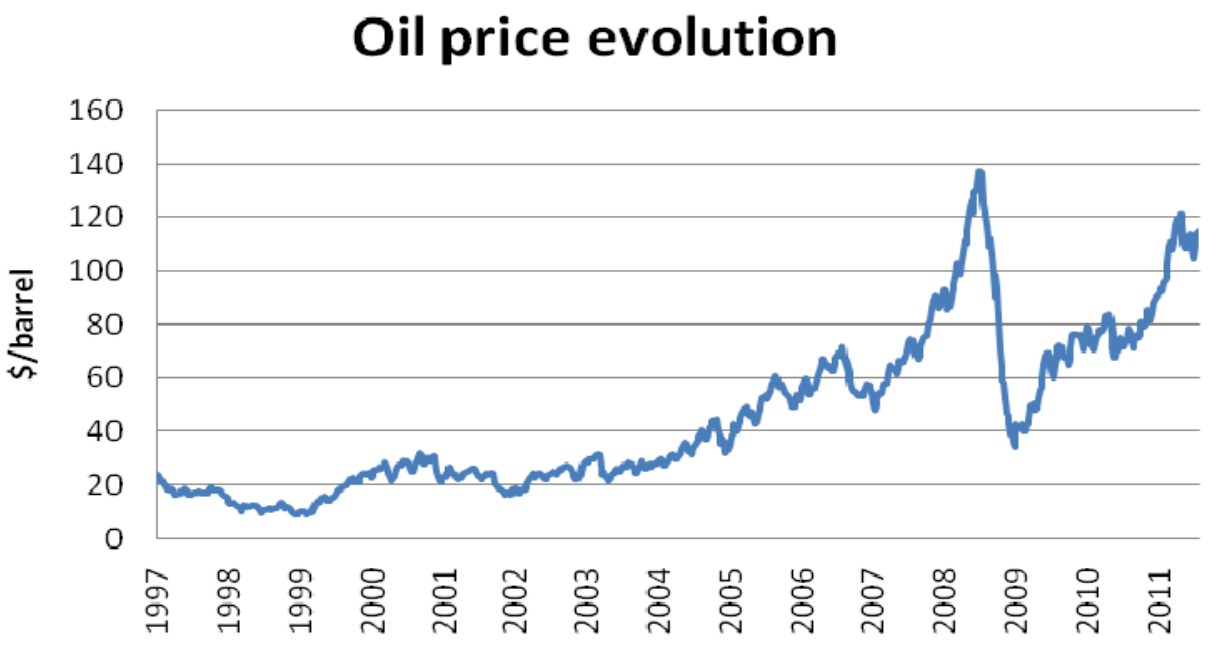

Another important factor to consider is the large scale financial speculation, apart from the ongoing geo-political conditions (oil prices may rise due to political situations involving producing countries).

Figure 6 shows the evolution of oil prices in recent decades. It shows the great variability of the price and the mathematical complexity of this development model [25]. However, to obtain a more realistic model, the fixed oil price (the value at the beginning of 2010) has been included [26]. The forecast values in oil prices in dollars/barrel are: 
Table 1. Oil prices forecasted [26].

\begin{tabular}{llllllllllll}
\hline YEAR & $\mathbf{2 0 1 0}$ & $\mathbf{2 0 1 1}$ & $\mathbf{2 0 1 2}$ & $\mathbf{2 0 1 3}$ & $\mathbf{2 0 1 4}$ & $\mathbf{2 0 1 5}$ & $\mathbf{2 0 1 6}$ & $\mathbf{2 0 1 7}$ & $\mathbf{2 0 1 8}$ & $\mathbf{2 0 1 9}$ & $\mathbf{2 0 2 0}$ \\
\hline PRICE & 70.30 & 73.06 & 79.41 & 85.74 & 90.91 & 94.52 & 98.23 & 101.23 & 104.41 & 106.47 & 108.28 \\
\hline
\end{tabular}

The tax regulations fixed by Spanish legislation need to be added to this oil price, as well as transport and the profit margin of gas stations. According to data from the "Market Observatory for Energy" [26], indirect taxes for gasoline are $436.47 €$ per 1000 liters, while for diesel fuels they are $340.36 €$ per 1000 liters. The V.A.T. tax in Spain is at $18 \%$, and the profit margin of gas stations in Spain is about $25 \%$.

Finally, we estimated the maintenance costs that conventional vehicles will have on an annual basis. For this, we estimated the maintenance costs that a conventional vehicle has over its useful lifetime, and this estimation has been done taking into account the number of kilometers a vehicle does on average before it needs to be replaced. The value will be set by external studies that determine the value as $0.03 €$ per kilometer covered [11,27]. If this value is multiplied by the average annual kilometers traveled by a vehicle, this will have, as a result, an economic value which is the amount that the customer spends on an annual basis on conventional vehicle maintenance.

For the running costs of the electric vehicle, the schema is similar to that of the conventional vehicle: There is an annual cost due to vehicle consumption and other costs due to maintenance.

The annual cost derived from the electric vehicle consumption is calculated based on the price of electricity, but it is necessary to take into account various considerations: the number of users that will have a suitably equipped garage, the number of users that will recharge by night, by day, the driving patterns [21], etc.

Figure 7. Driving patterns [21].

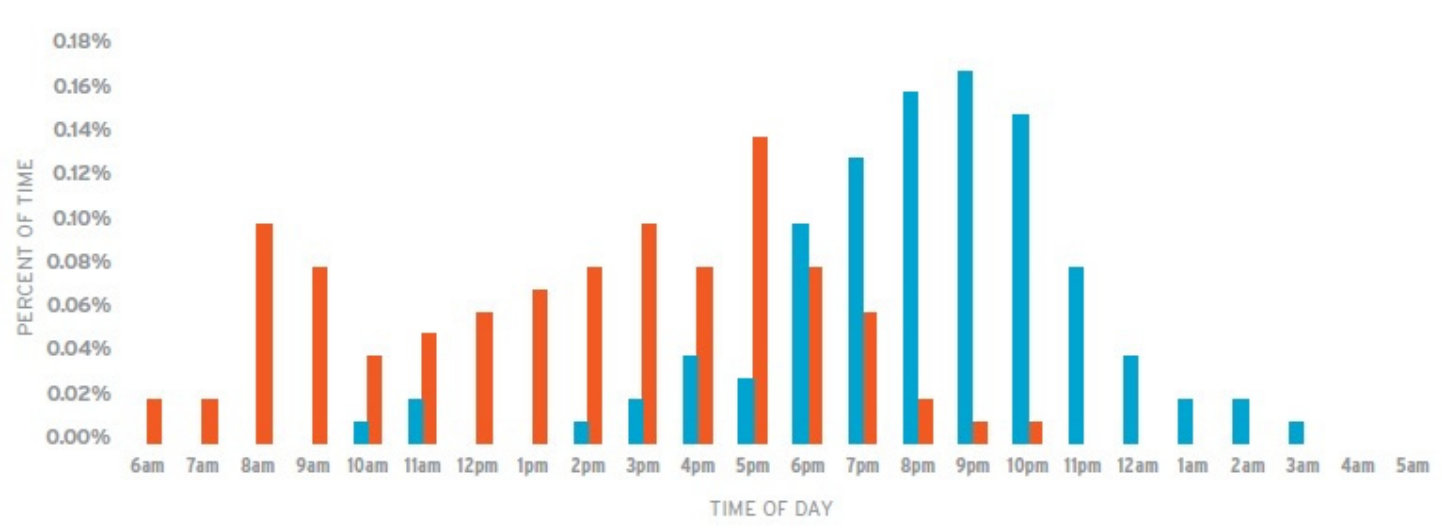

The first consideration is to assume that most users with electric vehicles will have a garage (as seen before) and most of them (80\% [22]) will recharge the car at night. This value is also supported by studies in pilot positions analyzing the patterns of use of the electric vehicle and its recharge rate. Figure 7 shows the results of a study of "The Idaho National Laboratory" [21]. It can be clearly seen how the majority of recharges are done during a period when the vehicle is not in use, at nighttime.

According to this, the prices of recharge during the day, the evening and at the reduced rate called "Super Off-peak Tariff", given by the Government of Spain, were studied. The last rate is designed to 
support the charges of electric vehicles made during the night, and thereby improve the recharge curve as explained above, as reflected in the "Strategy to Promote Electric Vehicles in Spain" [28]. Since there is still no information on this rate, we estimated a maximum cost per kWh that would give this rate-calculated value at $50 \%$ of the cost of electricity during the night. This value has been taken in a somewhat arbitrary way, since, as mentioned above, there is no information yet on this rate, but it is considered that this value of $\mathrm{kWh}$ could achieve the results anticipated at this rate.

With the values of all rates and the estimations of the potential users of each rate, the average price of electricity has been obtained. As happened with oil prices, obtaining an estimate of the price of electricity in Spain is extremely difficult, but it has been necessary to make this estimate for a more realistic model. Data based on from the values from recent years cannot be extrapolated, given the continuous modification of the rates due to a tariff deficit of the electrical system.

The tariff deficit is the difference between the actual cost of electricity production (both production and transport and distribution) and the fixed rate. This generates a debt that is accumulated every year. Because of this, the fluctuation in prices is difficult to quantify. According to this, the approach indicated by the European Commission for Energy has been used, given by the curve shown in the Figure 8.

Figure 8. Electricity price forecast [29].

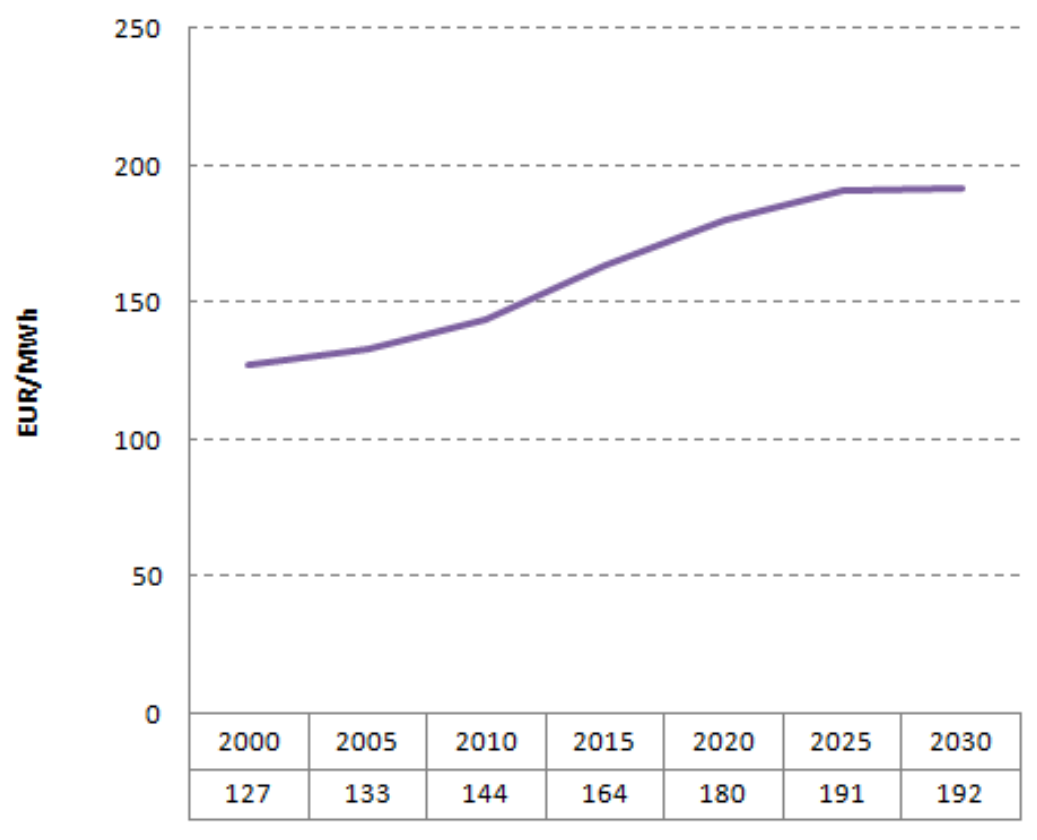

Finally, it is necessary to estimate the maintenance costs in the same way as for conventional vehicles, that is, relative to the number of kilometers a vehicle does on average before it needs to be replaced. In this case, the value will be set by external studies that determine the value as $0.02 €$ per kilometer [11,30].

By multiplying this value by the average annual miles traveled by a vehicle, you get the economic value that the customer spends annually to maintain the electric vehicle. As can be seen, the maintenance cost per kilometer is significantly lower compared to the conventional vehicle $(33 \%$ lower). This is because electric motors do not have a large variety of working parts, which means that a continuous maintenance, as exhaustive as in internal combustion engines, is not necessary. In fact, 
the electric motor has one moving part, the shaft, which is very reliable and requires little or no maintenance. Another important factor is the elimination of oil, which implies that it is not necessary to make periodic oil changes. In the electric vehicle, drive systems do not exist, as nor do fuel pumps or injection, which also minimizes maintenance [8]. The fact that the electric motor is simpler than the internal combustion engine reduces the risk of breakdowns.

To summarize, we can determine that the TCO is described by the following expression:

$$
\mathrm{TCO}=\text { Purchasing cost }(y)+\sum_{t=y}^{2020}(\text { Fuel cost }(t)+\text { Maintenance cost })
$$

where " $y$ " is the year of purchase. As explained above, the annual costs for both kinds of vehicles are determined by fuel costs and maintenance costs from the vehicle purchasing year until the year 2020, the year when the simulation ends. Obviously, these costs are variable in time due to variations in the fuel prices previously explained, as well as the number of kilometers traveled on average each year.

Once all input data have been determined and modeled, the output data is the number of years that the potential clients take to recover their investment, comparing how long it takes for it to be more profitable to buy an electric vehicle than a conventional vehicle. This value will depend on the timeframe when purchasing the vehicle.

According to the number of years for repayment, the purchase of electric vehicles, compared to conventional vehicles, will have a different appeal to the potential customer, resulting in a percentage of the population that will potentially want to buy an electric vehicle in Spain.

This result, added to the rest of the results from the other blocks of the model, enables us to obtain the estimated number of vehicles that could run on Spanish roads in the coming years under our assumptions.

It is important to note that, although the economic is the main factor when purchasing a new vehicle, there is no direct correlation between the price of the vehicle and the number of existing electric vehicles on the roads. For the full study and the final results, other factors have been used, such as the autonomy of electric vehicle, advertisements and information, recharging points and "word of mouth".

\section{Results}

As explained before, the scenarios to analyze are related with the economic factor, keeping the baseline scenario for the other variables not analyzed in this paper. The first scenario to be analyzed corresponds to the baseline model, based on data that we know today for Spain; that is, a forecast model in terms of the likely evolution of the batteries and the non-implementation of battery exchange stations [31] and with the estimated average battery cost. We could say that this is the reference state. To combine these data, it is assumed that government subsidies are known until this time, i.e., 7,000 $€$ for the purchase. As for the cost of the battery, according to the average forecast in 2020, the cost per $\mathrm{kWh}$ will be close to $243 €$ [21], implying that a full battery will cost about $6,500 €$. According to the model and the average forecasts in all fields, we find that the number of vehicles in 2020 would be around 700,000 (Figure 9). 
Figure 9. Electric vehicles on Spanish roads (the authors' calculations).

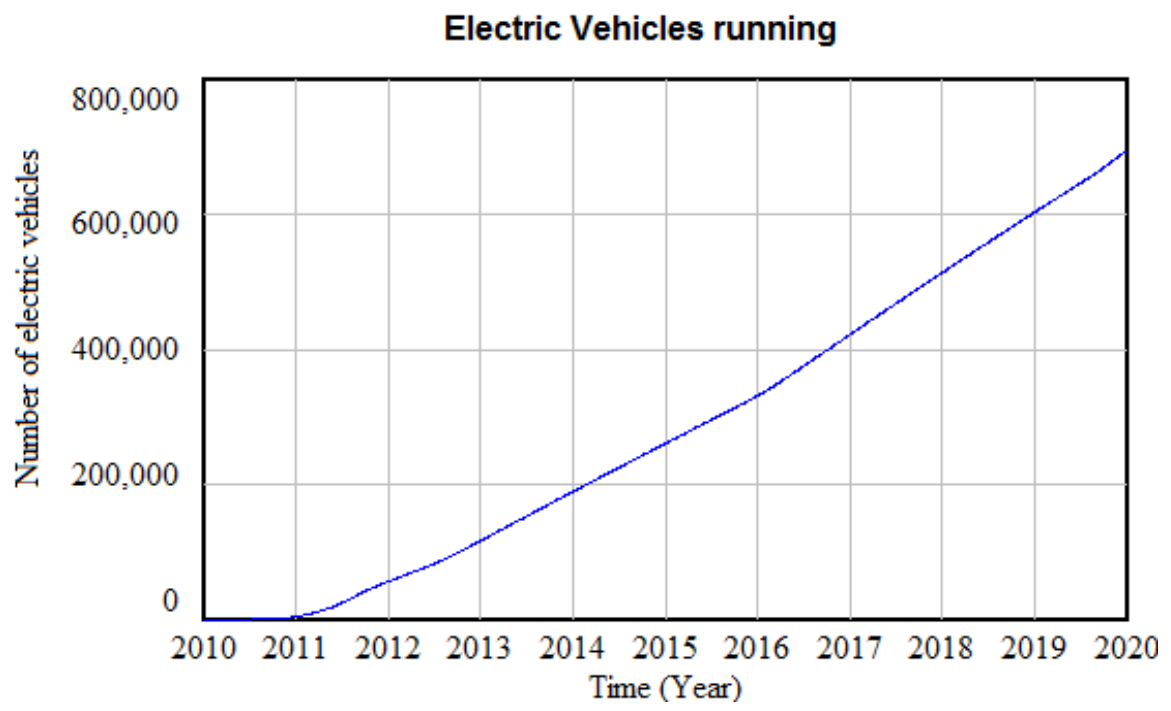

Figure 10. TON of $\mathrm{CO}_{2}$ not emitted (the authors' calculations).

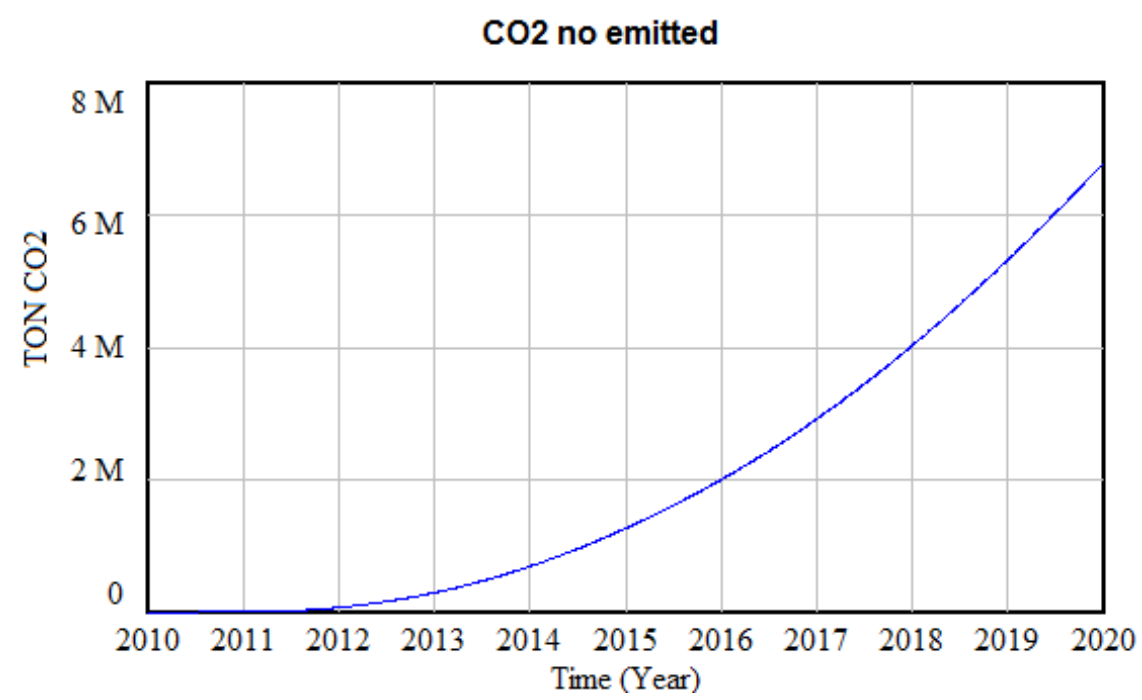

This figure corresponds to a number of $\mathrm{CO}_{2}$ tons not emitted to the atmosphere of more than 6 million (Figure 10). To calculate the $\mathrm{CO}_{2}$ not emitted, the replacement of a conventional vehicle by an electric vehicle is assumed. In this first stage of the electric vehicle commercialization, it is only expected to reach the "early market", that is, the market formed by the "innovators" such as car enthusiasts and environmentalists [30]. Due to the small size of this group (less than $2.5 \%$ of global demand), the so-called "rebound effect" due to the temporal space covered by the study is not expected [32].

Although the electric vehicle obtains a reduction in $\mathrm{CO}_{2}$ emissions because it does not generate emissions during its use due to the electric engine, there are emissions generated in the production of the electrical energy used by the vehicle. Accordingly, there is an emission displacement, but as mentioned above, the total energy balance (Well-To-Wheel) still indicates a significant reduction in $\mathrm{CO}_{2}$ emissions [33].

The following scenarios are designed to study the evolution of the cost of the battery. As seen before, the cost of the battery is decisive in the evolution of electric vehicle demand. For the analysis 
of this battery development, two scenarios are considered in addition to the baseline: the optimistic scenario with an annual decrease of $10 \%$ in $\mathrm{kWh}$ of the battery (corresponding to a major evolution of electric vehicle sales worldwide, making the cost of the battery dramatically lower due to mass production), and one pessimistic, with an annual decrease of $4 \%$ in the price of the battery (this scenario represents a poor use of electric vehicles, where mass production of batteries has failed to take off sufficiently in order to achieve a significant reduction in the price). The baseline scenario is a decrease of $7 \%$. Figure 11 shows the cost of the battery under the various scenarios.

Figure 11. Forecast of battery cost in the optimistic, pessimistic and baseline scenarios (own calculations).

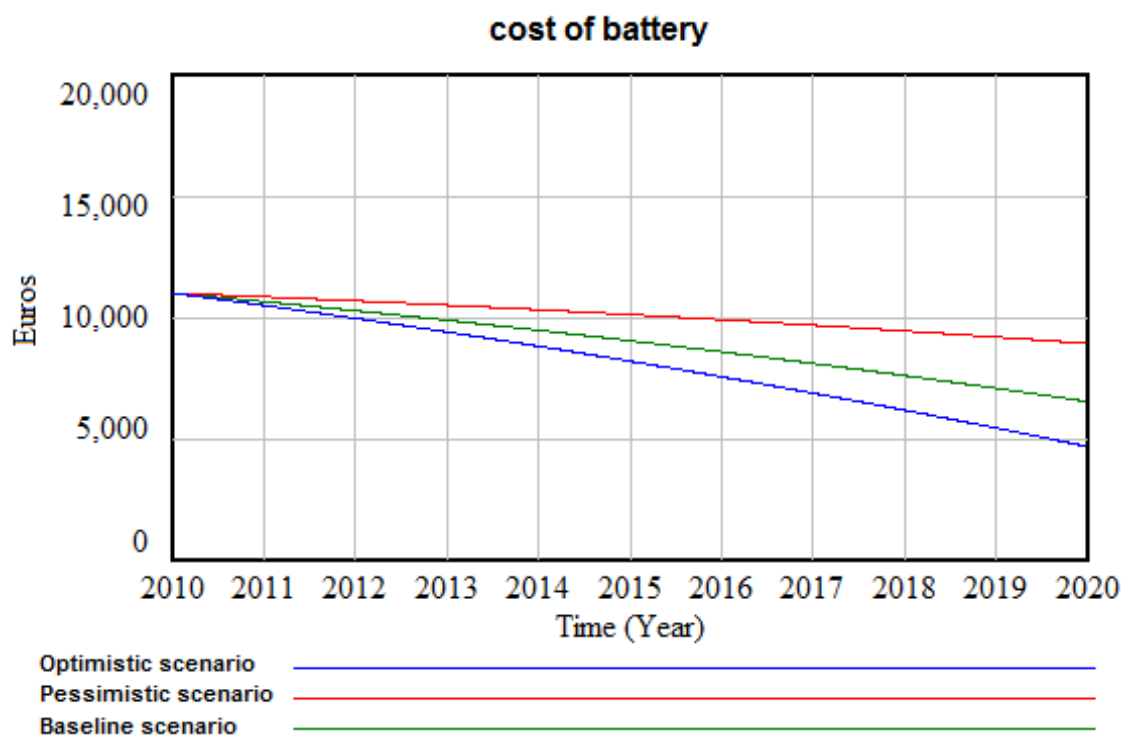

In these three cases, the electric vehicle fleet evolves as follows (Figure 12):

Figure 12. Electric vehicles on roads for the optimistic, pessimistic and baseline scenarios (the authors' calculations).

\section{Electric vehicles running}

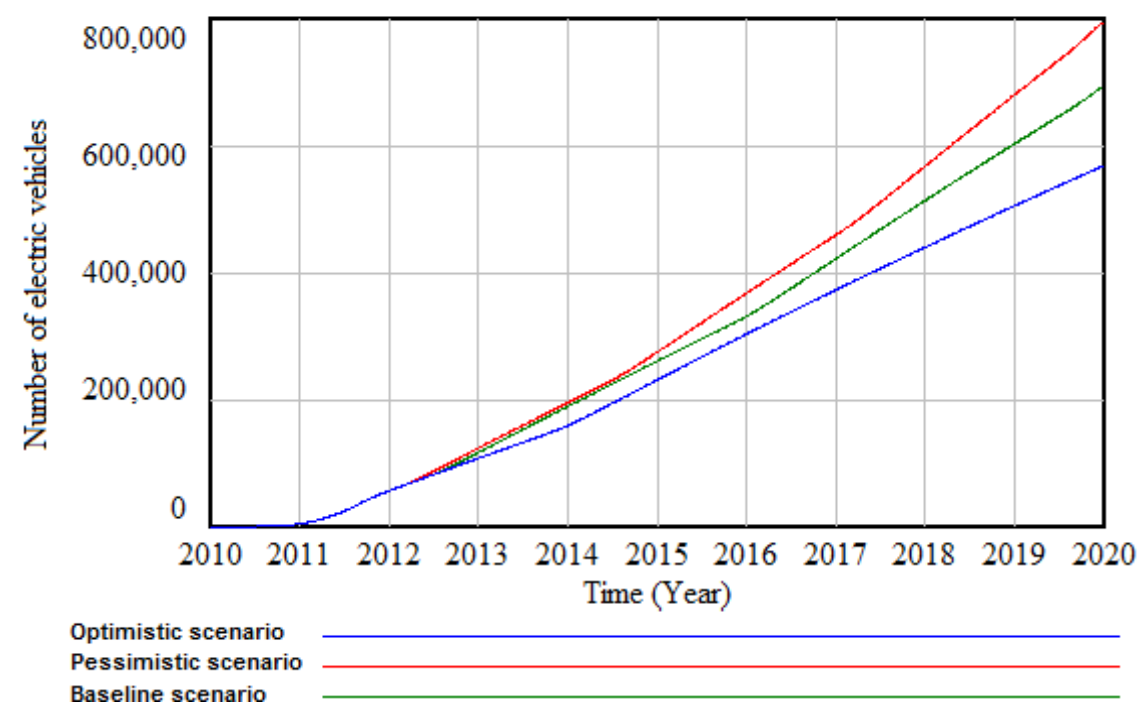


It can be seen that, in 2013 and the following years, there is a clear difference between the various scenarios. This is because the battery capacity in these early years of commercialization of electric vehicles is relatively small $(22 \mathrm{kWh})$. The value of $\mathrm{kWh}$ between scenarios in 2013 ranged between values of 364 and $442 €$, i.e., about $80 €$ of difference, which, increased by $22 \mathrm{kWh}$, is approximately $1,700 €$. As the battery increases in capacity, this price difference becomes more significant. This can clearly be seen in the graph of the average price of electric vehicles with the current values of the facilities (Figure 13).

Figure 13. Electric vehicle price for the optimistic, pessimistic and baseline scenarios (own calculations).

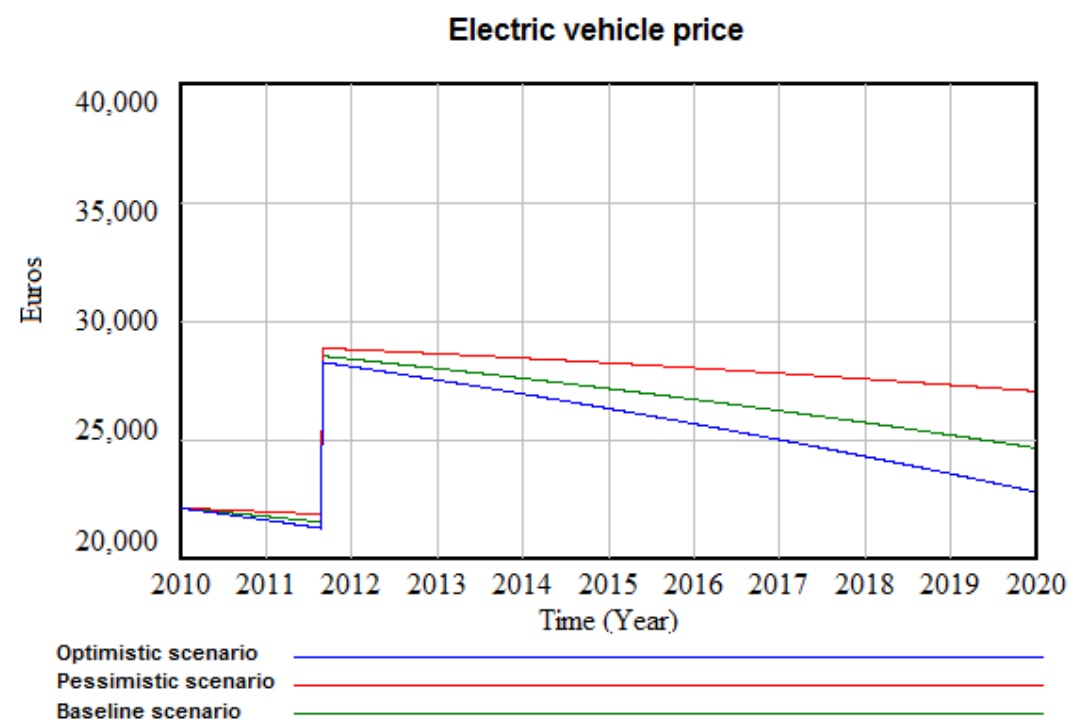

As seen before, the price of the electric vehicle grows so much during 2012 due to the end of subsidies currently approved by the Spanish government. If government support in the form of a subsidy for purchasing electric vehicles is stopped, the targets will not be achieved. Figure 14 shows the optimistic scenario of reducing the cost of the battery in relation to government objectives.

Figure 14. Electric vehicle fleet compared to the Government target for the optimistic scenario without subsidies in 2013 (the authors' calculations).

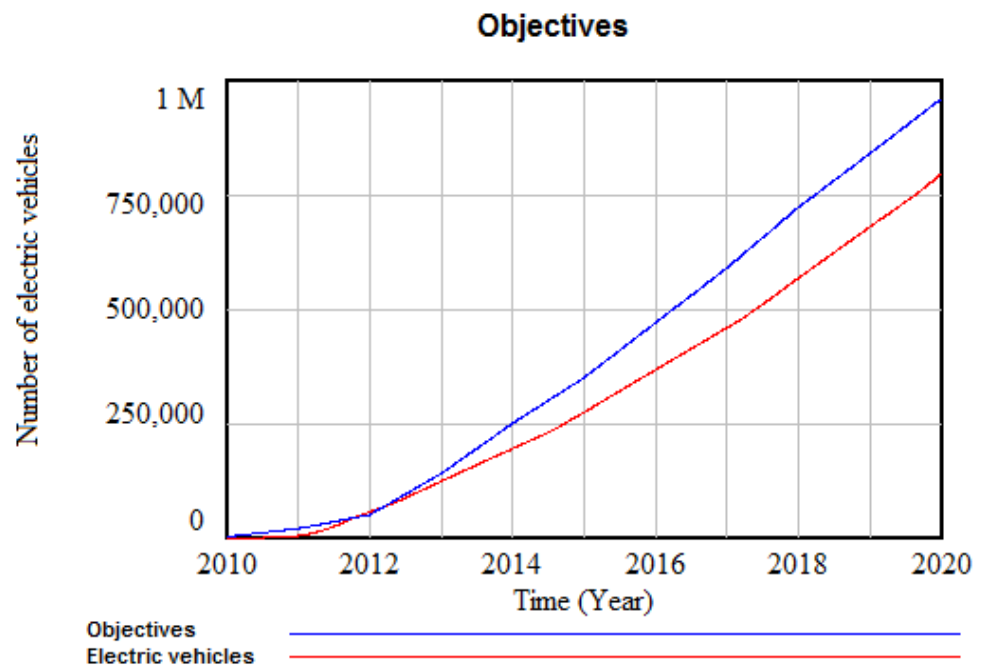


If we keep the subsidies of $7,000 €$ constant in time for the optimistic scenario, the following results are obtained (Figure 15).

Figure 15. Electric vehicle fleet compared to the Government target for the optimistic scenario with subsidies until 2020 (the authors' calculations).

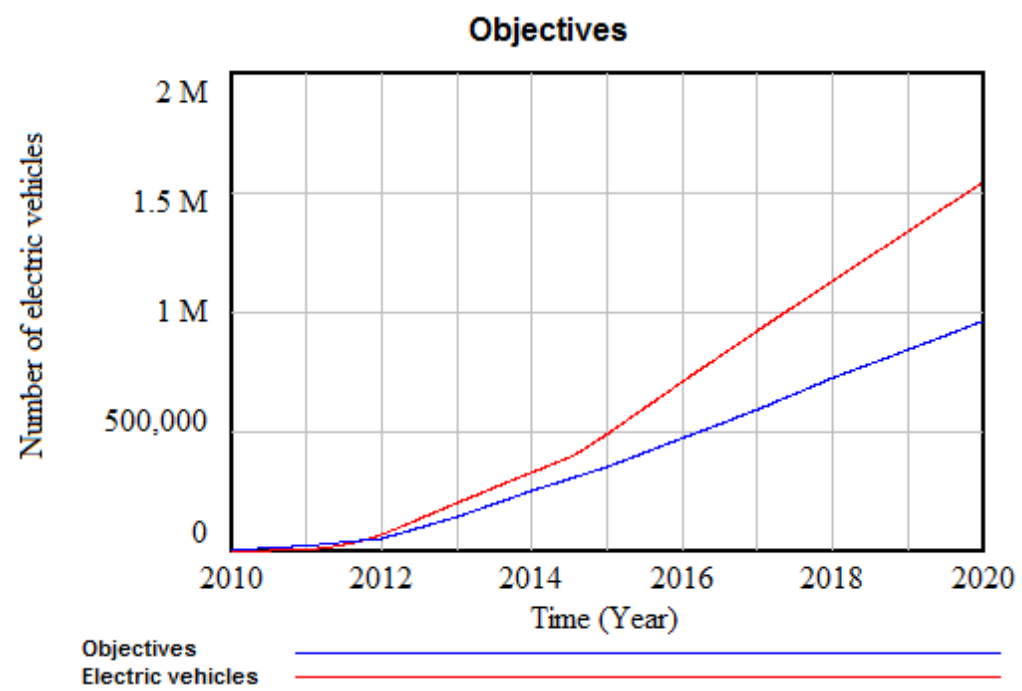

In this case, the results are well above the targets set, but at an exorbitant cost (close to 14,000 million Euros). By performing various simulations, we can determine that in the optimistic scenario of reducing the cost of the battery, with a subsidy value of 2,000 $€$ from 2012, the government achieves the objectives until at least 2016, and there is a slight difference in subsequent years, only converging after 2020 .

Figure 16. Electric vehicle fleet compared to the Government target for the optimistic scenario with optimal subsidies until 2020 (the authors' calculations).

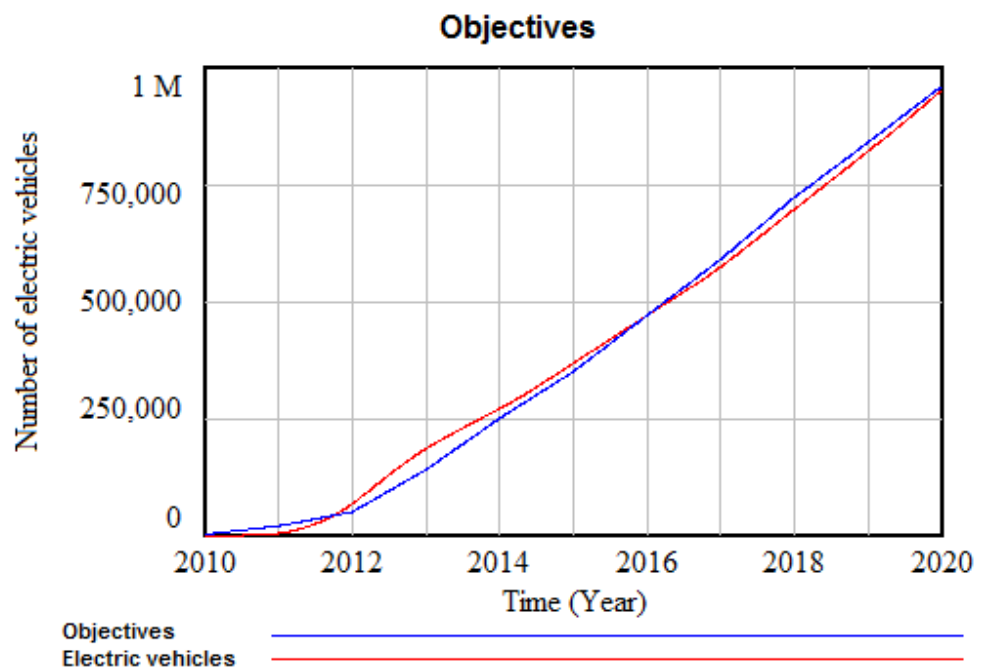

For $2,000 €$ of subsidy, the total government expenditure will be slightly in excess of 3,000 million Euros, which is a value quite consistent with the current government budget (remember that, for the years 2011 and 2012, the budget was 240 million Euros) (Figure 17). 
Figure 17. Electric vehicle fleet compared to the Government target for the pessimistic scenario without subsidies until 2020 (the authors' calculations).

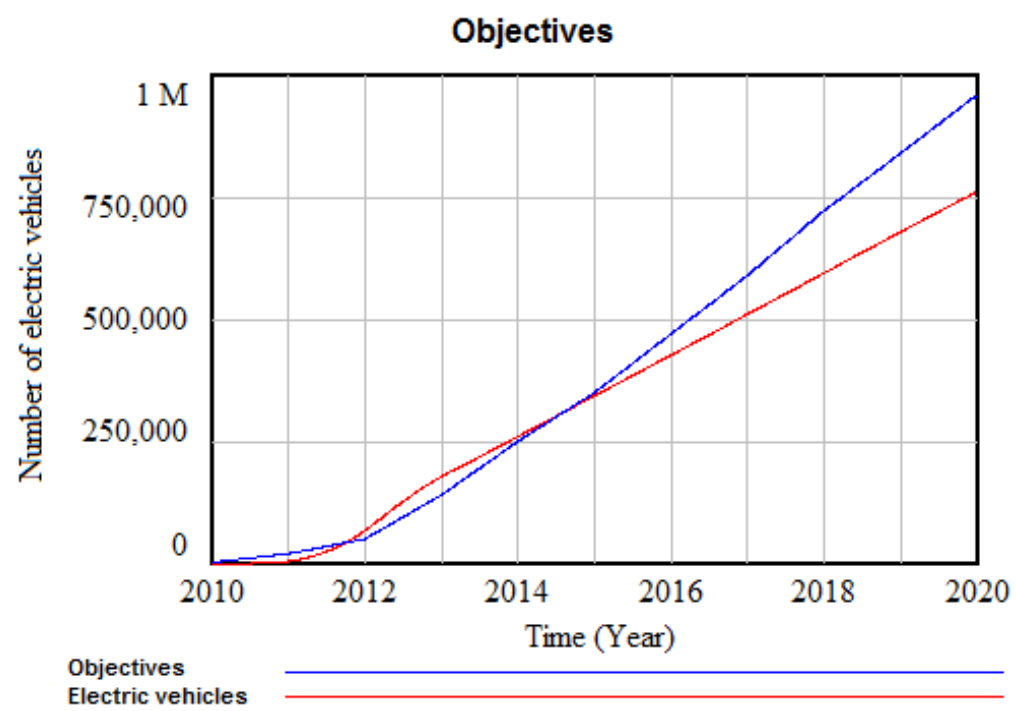

The case of the pessimistic scenario is quite different from the optimistic one, given the value of the subsidies necessary to achieve the objectives. When using the estimated value of 2,000€ for the optimistic scenario, we find that the goal is met until 2014, but as the battery capacity increases over time, demand for electric vehicles will decrease, since they will lose competitiveness against conventional vehicles, due to high additional costs. In this case, the optimal value of the subsidies, after making several simulations, were obtained for values between 4,500 $€$ and 5,000 $€$, implying a cost to the government of nearly 6,000 million Euros (Figure 18).

Figure 18. Electric vehicle fleet compared to the Government target for the pessimistic scenario with the optimal subsidies until 2020 (the authors' calculations).

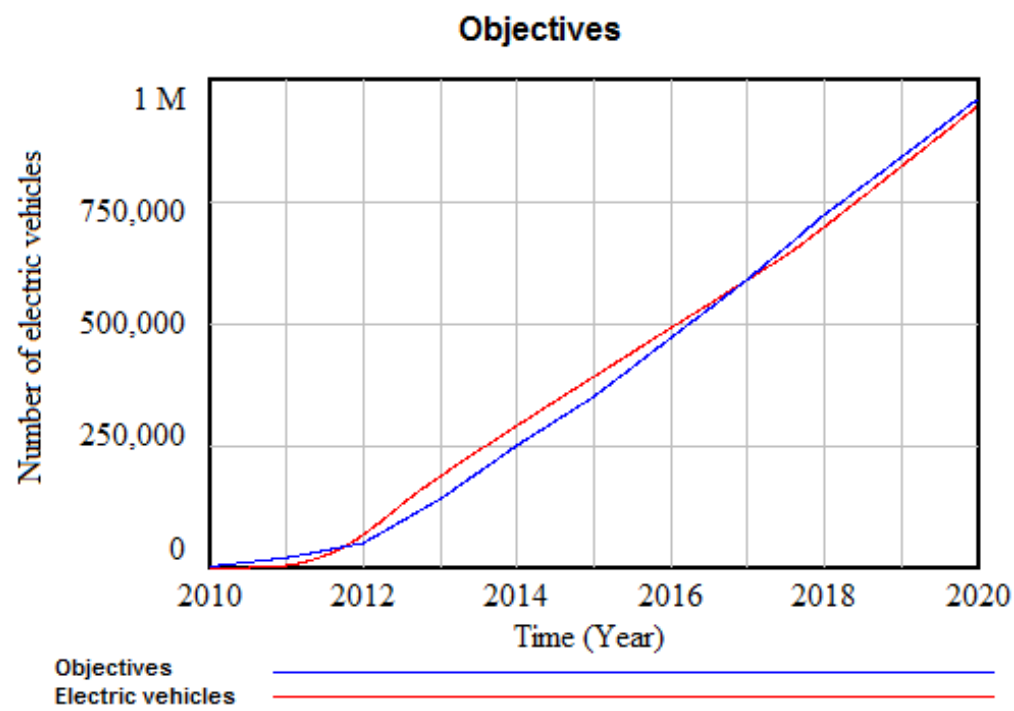

In view of the results, which can be determined taking into account the decrease in the cost of the $\mathrm{kWh}$ battery that will exist in coming years, the value of the subsidies to be given for the purchase of electric vehicles will range from $2,000 €$ in the optimistic case and up to 5,000 $€$ in the pessimistic case. 


\section{Conclusions}

The proposed model based on System Dynamics, provides a structure and framework to understand the behavior of the electric vehicle market according to the behavior of the main variables involved and the different scenarios. The key factors to integrate energy policies with market and customer criteria have been shown and quantified. The simulations help to understand the problem and forecast the evolution of electric vehicles in Spain under different hypotheses.

According to the simulation results, regardless of technological developments that may occur in the coming years, if government subsidies are limited to 2012, the current targets set for 2020 concerning the number of electric vehicles circulating on Spanish roads will not be achieved.

In view of the analysis of the results of the different scenarios, for a good implementation of electric vehicles, a major government outlay to subsidize the purchase will be needed. The acquisition of electric vehicles compared to conventional ones has a cost which is not always accepted by the consumer (although it will be compensated for in the use of the vehicle). In none of the scenarios discussed (even in the most optimistic scenario) are the desired results obtained if subsidies to them are the potential buyer are discontinued. While it is true that the value of the subsidies provided today will not be necessary in the near future, being able to significantly reduce this amount appears to be necessary, at least until 2020.

In fact, the economic factor is so important that, for the potential client, the scenarios of the evolution of vehicle autonomy will not prevail over the economic aspect. Moreover, according to the results of the simulations, the customer will prefer a vehicle with less autonomy, but at a lower cost. Therefore, although there will be significant technological improvements, an extra financial contribution will still be needed when the vehicle is purchased.

Briefly, if the Spanish government maintains its goals for electric vehicles and there is no unexpected technological leap, new economic or financial policies will be needed to support the electric vehicle market. The quantitative results about possible subsidies are only guideline values and they are conditioned by the proposed hypothesis and scenarios.

\section{References}

1. Ministerio de Industria, Comercio y Turismo. IDAE. Proyecto Movele. Proyecto piloto de demostración de viabilidad del vehículo eléctrico, 2009. Available online: http://www.idae.es/ index.php/mod.documentos/mem.descarga?file=/documentos_Cuadriptico_MOVELE_Final_fac4 a8ee.pdf (accessed on 6 July 2010).

2. Bandivadekar, A.; Bodek, K.; Cheah, L.; Evans, C.; Groode, T.; Heywood, J.; Kasseris, E.; Kromer, M.; Weiss, M. On the Road in 2035: Reducing Transportation's Petroleum Consumption and GHG Emissions; Massachusetts Institute of Technology: Cambridge, MA, USA 2008. Available online: http://web.mit.edu/sloan-auto-lab/research/beforeh2/otr2035/On\%20the\%20 Road\% 20in\%202035_MIT_July\%202008.pdf (accessed on 7 May 2010).

3. European Council for Automotive R\&D. Well-to-Wheels Analysis of Future Automotive Fuels and Powertrains in the European Context, 2006. Available online: http://co2star.eu/publications/ Well_to_Wheels_Report_EU.pdf(accessed on 28 July 2010). 
4. Granovskii, M.; Dincer, I.; Rosen, M.A. Economic and environmental comparison of conventional, hybrid, electric and hydrogen fuel cell vehicles. J. Power Sources 2006, 159, 1186-1193.

5. Walther, G.; Wansart, J.; Kieckhäfer, K.; Schnieder, E.; Spengler, T.S. Impact assessment in the automotive industry: Mandatory market introduction of alternative powertrain technologies. Syst. Dyn. Rev. 2010, 26, 239-261.

6. Train, K.E.; Winston, C. Vehicle choice behavior and the declining market share of the US automakers. Int. Econ. Rev. 2007, 1469-1496.

7. Borenstein, S. Cost, Conflict and Climate: US Challenges in the World Oil Market, 2008. Available online: http://ucei.berkeley.edu/PDF/csemwp177.pdf (accessed on 2 April 2011).

8. Werber, M.; Fischer, M.; Schwartz, P. Batteries: Lower cost than gasoline? Energy Policy 2009, 37, 2465-2468.

9. Duvall, M.; Browning, L.; Kalhammer, F.; Warf, W.; Taylor, D.; Wehrey, M.; Pinsky, N. Advanced Batteries for Electric-Drive Vehicles: A Technology and Cost-Effectiveness Assessment for Battery Electric Vehicles, Power Assist Hybrid Electric Vehicles, and Plug-in Hybrid Electric Vehicles; Electric Power Research Institute: Palo Alto, CA, USA, 2004. Available online: http://www.spinnovation.comsn/Batteries/Advanced_Batteries_for_Electric-Drive_Vehicles.pdf (accessed on 9 August 2011).

10. Graham, R. Comparing the Benefits and Impacts of Hybrid Electric Vehicle Options; Electric Power Research Institute: Palo Alto, CA, USA 2001. Available online: http://www.ourenergypolicy. org/docs/9/Comparing_Hybrid_Electric_Vehicle_Options.pdf (accessed on 10 August 2011).

11. Neenan, B. Characterizing Consumers' Interest in and Infrastructure Expectations for Electric Vehicles: Research Design and Survey Results; Electric Power Research Institute: Palo Alto, CA and Southern California Edison, Rosemead, CA, USA, 2010. Available online: http://my.epri.com/ portal/server.pt?Abstract_id $=000000000001021285$ (accessed on 10 August 2011).

12. Kurani, K.; Axsen, J.; Caperello, N.; Davies, J.; Stillwater, T. Plug-In Hybrid Electric Vehicle (PHEV) Demonstration and Consumer Education Outread, and Market Research Program; Institute of Transportation Studies, University of California: Davis, CA, USA, 2009. Available online: http://pubs.its.ucdavis.edu/download_pdf.php?id=1310 (accessed on 6 August 2011).

13. Kurani, K.; Axsen, J.; Burke, A. Batteries for Plug-in Hybrid Electric Vehicles (PHEVs): Goals and the State of Technology circa 2008; Institute of Transportation Studies, University of California: Davis, CA, USA, 2008. Available online: http://pubs.its.ucdavis.edu/download_pdf. php?id=1169 (accessed on 6 August 2011).

14. Lumbreras, J.; Valdés, M.; Borge, R.; Rodríguez, M.E. Assessment of vehicle emissions projections in Madrid (Spain) from 2004 to 2012 considering several control strategies. Transp. Res. Part A 2008, 42, 646-658.

15. Geels, F.W. From sectoral systems of innovation to socio-technical systems Insights about dynamics and change from sociology and institutional theory. Res. Policy 2004, 33, 897-920.

16. Sterman, J.D. Business Dynamics: Systems Thinking and Modeling for a Complex World; Irwin McGraw-Hill: Burr Ridge, IL, USA, 2000. 
17. Brickert, S.; Kuckshinrichs, W. Electromobility as a Technical Concept in an Ecological Mobility Sector? An Analysis of Costs. In Proceedings of the 9th International Conference of the European Society for Ecological Economics (ESEE 2011), Istanbul, Turkey, 14-17 June 2011; Available online: http://www.esee2011.org/registration/fullpapers/esee2011_54ff9e_2_1307627504 8295_2080.pdf (accessed on 6 August 2011).

18. Blesl, M.; Bruchof, D.; Hartmann, N.; Özdemir, D.; Fahl, U.; Eltrop, L.; Voß, A. Entwicklungsstand und Perspektiven der Elektro-mobilität. Universität Stuttgart Institut für Energiewirtschaft und Rationelle Energieanwendung: Stuttgart, Germany 2009. Available online: http://elib.uni-stuttgart.de/opus/volltexte/2010/5218/pdf/Elektromobilitaet_Endbericht_20100322.pdf (accessed on 7 August 2011).

19. Hensley, R.; Knupfer, S.; Pinner, D. McKinsey Quarterly, n³. Electrifying Cars: How Three Industries Will Evolve. Available online: http://www.mckinseyquarterly.com/Electrifying_cars_ How_three_industries_will_evolve_2370 (accessed on 7 April 2010).

20. Kromer, M.A.; Heywood, J.B. Electric Powertrains: Opportunities and Challenges in the U.S. Light-Duty Vehicle Fleet; Laboratory for Energy and the Environment, Massachusetts Institute of Technology: Cambridge, MA, USA, 2007. Available online: http://web.mit.edu/sloan-autolab/research/beforeh2/files/kromer_electric_powertrains.pdf (accessed on 7 April 2010).

21. Electrification Coalition. Electrification Roadmap. Revolutionizing Transportation and Achieving Energy Security. Available online: http://www.electrificationcoalition.org/sites/default/files/ SAF_1213_EC-Roadmap_v12_Online.pdf (accessed on 7 April 2010).

22. Royal Automobile Club of Spain Website. Available online: http://www.race.es/ (accessed on 15 April 2010).

23. Club Español de la Energía. Instituto Español de la Energía. Cuadernos de Energía, n²6, octubre de 2009. Available online: http://www.enerclub.es/files/frontAction.do?action=getFile\&fileID= 1000056208 (accessed on 4 June 2010).

24. Traffic Department website. Available online: http://www.dgt.es/portal/ (accessed on 25 April 2010).

25. U. S. Energy Information Administration website. Available online: http://www.eia.gov (accessed on 2 February 2011).

26. U.S. Energy Information Administration. Annual Energy Outlook 2010. Available online: http://www.eia.gov/oiaf/archive/aeo10/pdf/0383\%282010\%29.pdf (accessed on 28 July 2011).

27. Pistoia, G. Electric and Hybrid Vehicles: Power Sources, Models, Sustainability, Infrastructure and the Market; Elsevier: Amsterdam, The Netherlands, 2010.

28. Ministerio de Industria, Comercio y Turismo. Estrategia integral para el impulso del vehículo eléctrico en España; Ministerio de Industria, Comercio y Turismo: Madrid, Spain, 2010.

29. European Commission Directorate-General for Energy and Transport European Energy and Transport, Trends to 2030-Update 2009. 2010. Available online: http://ec.europa.eu/energy/ observatory/trends_2030/doc/trends_to_2030_update_2009.pdf (accessed on 28 July 2011).

30. Moore, G.A. Crossing the Chasm; Harperbusiness: New York, NY, USA, 1991.

31. Better Place Website. Available online: http://www.betterplace.com/ (accessed on 2 February 2011).

32. Greening L.A.; Greene, D.L.; Difiglio C. Energy efficiency and consumption-The rebound effect-A survey. Energy Policy 2000, 28, 389-401. 
33. Thiel, C.; Perujo, A.; Mercier, A. Cost and $\mathrm{CO}_{2}$ aspects of future vehicle options in Europe under new energy policy scenarios. Energy Policy 2010, 38, 7142-7151.

(C) 2012 by the authors; licensee MDPI, Basel, Switzerland. This article is an open access article distributed under the terms and conditions of the Creative Commons Attribution license (http://creativecommons.org/licenses/by/3.0/). 